Bol. Acad. peru. leng. 69. 2021 (399-401)

\title{
Diccionario de variantes del español
}

\author{
Lauro Capdevila \\ Ministère de l'Éducation Nationale, París, Francia \\ lauro.capdevila@gmail.com \\ https://orcid.org/0000-0002-1996-7532
}

Recibido: 13/08/2020 Aceptado: 27/02/2021 Publicado: 30/06/2021

El Diccionario de variantes del español es una obra en línea de acceso libre y gratuito (http://diccionariovariantesespañol.org/)

Su meta es identificar y registrar con la mayor objetividad posible las variantes diatópicas, diafásicas y diastráticas del español usual de América, España y África del siglo XXI. De este proyecto coherente, derivan las diferentes características de la obra detalladas a continuación.

- Se proporcionan sistemáticamente referencias de los vocablos, expresiones y construcciones bajo forma de citas textuales comprobadas en la línea de los diccionarios de autoridades. Dichas citas remiten a los diferentes contextos de habla sin exclusiva: populares, académicos, malsonantes, urbanos, rurales, infantiles, jergales, etc.

https://doi.org/10.46744/bapl.202101.016 
- La recopilación se fundamenta en fuentes diversificadas: notas de prensa, artículos especializados, columnas, sociales, cartas de lectores, novelas, cuentos, ensayos, blogs de confianza, etc. Una sección del diccionario ofrece al usuario o al investigador interesado los datos de identificación de los documentos originales: autor, título, obra o diario, fecha, ISBN.

- Ya que desde un punto de vista objetivo no hay motivo para considerar como normativas ciertas formas peninsulares del castellano, se registran en igualdad de condiciones las diferentes palabras, expresiones y construcciones usadas en los distintos países donde el español es lengua de comunicación corriente, incluyendo los Estados Unidos. En pocas palabras, se respetan todas las formas de hablar.

- Por supuesto, la distribución de las palabras, expresiones y construcciones con sus distintas acepciones no coincide con las fronteras nacionales y se podría trazar una infinidad de mapas lingüísticos a escalas diferentes. Hemos optado por el nivel nacional, que, por razones prácticas, es el adoptado y homogeneizado por casi todos los medios de comunicación.

- El proyecto de cartografiar las variantes del español supone considerar las escalas relativas y conformarse a la realidad demográfica de la lengua teniendo en cuenta la fracción que representa cada población hispanohablante en el panorama global. Una sección de estadísticas ofrece una relación precisa de las ocurrencias por países y de su evolución. El afán es lograr un equilibrio fiel a la realidad.

- Las palabras, expresiones y acepciones que constan en la obra son aquellas que un hispanohablante puede no comprender o entender de forma errónea. Por ejemplo, el vocablo ñeque se refiere a un animal que un ecuatoguineano a menudo ignora y que un argentino conoce bajo otro nombre. En ambas circunstancias se hace evidente la necesidad de aclarar el sentido de la palabra. Otro caso es el de la palabra roble que puede ser comprendida tanto por un caribeño como por un español, aun cuando corresponde a dos árboles muy distintos para uno y otro. Por tanto, se han incluido la palabra neque y las distintas acepciones de roble. El diccionario presta tanta atención al significado como al significante. 
https://doi.org/10.46744/bapl.202101.016

- Se dedica una especial atención a las variantes de las construcciones gramáticas y regímenes de verbos y adjetivos a veces dejados de lado. Se conocen las alternancias alen, por/para, pero obviamente hay muchas más.

- Como registro de variantes, la obra es fundamentalmente un diccionario de sinónimos y, de ningún modo, un diccionario enciclopédico. La obra no describe, sino que da las equivalencias y correspondencias para que el lector pueda orientarse perfectamente. Las definiciones, escuetas, solo aparecen cuando es preciso despejar dudas. En cambio, se proporcionan entre paréntesis los elementos de contexto a menudo decisivos. Una misma palabra puede tener acepciones muy diferentes según se refiere al deporte, a los sentimientos o a la economía.

- El Diccionario de variantes es diferencial, o sea, presenta las palabras, expresiones, acepciones y construcciones que difieren en cuanto al uso general. No se dan las que son conocidas en todos los países. Solo aparecen con la mención todos cuando puede existir una duda. Es el caso, por ejemplo, de la palabra neumático, conocida en todos los territorios de habla española a pesar de la gran variedad de términos usados en los diferentes países para designar esta pieza automovilística.

- La obra no pretende ser un diccionario exhaustivo, ni mucho menos, sino un proyecto en constante desarrollo. Actualmente cuenta ya con más de 40000 entradas y 63000 citas, y sigue recogiendo y agregando a diario nuevos vocablos y acepciones.

- Por tanto, se agradecen todas las observaciones y consultas de los usuarios e investigadores. El formulario para este menester se hallará sin dificultad bajo la pestaña contacto. Nos comprometemos a contestar.

- En resumidas cuentas, el Diccionario de variantes del español no pretende registrar el español como debería hablarse, sino como se habla. 